\title{
PENGEMBANGAN LKPD LITERASI SAINS BERBASIS LESSON STUDY FOR LEARNING
} COMMUNITY (LSLC)

\section{DEVELOPMENT OF SCIENCE LITERACY'S WORKSHEET BASED ON LESSON STUDY FOR LEARNING COMMUNITY (LSLC)}

\author{
Baiq Niswatul Khair*, Fitri Puji Astria, K. Sri Kusuma Wardani, Nurwahidah, dan N L P. Nina Sriwarthini \\ Program Studi Guru Sekolah Dasar, Universitas Mataram, Mataram, Indonesia. \\ *Email: baiqniswatul_fkip@unram.ac.id
}

Diterima: 22 Desember 2020. Disetujui: 30 Desember 2021. Dipublikasikan: 25 Januari 2021

\begin{abstract}
Abstrak: Penelitian ini bertujuan untuk menghasilkan LKPD literasi sains berbasis lesson study for learning community yang valid. Lembar kerja peserta didik (LKPD) yang dikembangkan ini merupakan LKPD yang spefisik untuk menfasilitasi siswa mengenal literasi sains. Adapun pola pengembangan LKPD literasi sains ini sendiri mengacu pada lesson study for learning community (LSLC) yang terdiri dari perencanaan, pelaksanaan, dan refleksi. Penelitian ini merupakan penelitian Research and Development (R \& D) dengan model 4D (define, design, develop, dan disseminate). Data dikumpulkan dengan menggunakan lembar validasi. Analisis data dilakukan dengan metode deskriptif kuantitatif terhadap validitas LKPD literasi sains berbasis lesson study for learning community. Hasil penelitian menunjukkan bahwa: 1) LKPD literasi sains berbasis lesson study for learning community dinyatakan valid dengan skor rata-rata $3.60,2)$ kepraktisan terhadap LKPD yang dikembangkan berada pada kriteria 3.80 oleh guru dan 3.50 oleh peserta didik. Berdasarkan hasil penelitian dapat disimpulkan bahwa LKPD literasi sains berbasis lesson study for learning community sangat valid dan praktis.
\end{abstract}

Kata Kunci: LKPD, Literasi Sains, LSLC

Abstract: The research aims to produce a valid science literacy's worksheet based on lesson study for learning community. This developed student worksheet is specific to facilitate students to recognize scientific literacy. The scientific literacy student activity worksheet development pattern itself refers to the lesson study for the learning community which consists of planning, implementation, and reflection. This research is a Research and Development (R \& D) with a 4D model (define, design, develop, and disseminate). Data were collected using a validation sheet. Data analysis was performed using quantitative descriptive methods on the validity of the lesson study-based learning community worksheet. The results showed that: 1) the lesson study for learning community-based science literacy's worksheet was declared valid with an average $3,60,2$ ) the responses by teachers and students to the developed student activities worksheet are in the criteria of 3,80 and 3,50, respectively. Based on the results of the study it was concluded that the lesson study for learning community-based science literacy worksheet is a very valid and practical.

Keywords: Student Activity Worksheet, Science Literacy, LSLC

\section{PENDAHULUAN}

Perubahan dan perkembangan dalam setiap aspek saat ini terus terjadi dengan cepat. Tak ada satupun petunjuk yang dapat mengarahkan kita untuk menetukan paradigma pendidikan yang baru, cara belajar baru maupun apa yang harus dipelajari dan dibutuhkan dimasa mendatang. Kecenderungan terjadinya perubahan dalam segala aspek kehidupan termasuk bidang pendidikan akan terus berlanjut. Meskipun beberapa aspek pendidikan tertentu akan tetap berlaku, namun kita harus menyiapkan diri untuk menerima berbagai perubahan aspek pendidikan dan pembelajaran yang lain seiring dengan perkembangan ilmu dan teknologi [1].

Paradigma pendidikan abad 21 mengacu pada keterampilan yang harus dimiliki para peserta didik dalam menghadapi tantangan pada era ini dan mampu memfasilitasi siswa dalam proses pembelajaran sehingga menciptakan suasana belajar aktif. [2]. National Education Association telah mengidentifikasi keterampilan abad ke-21 sebagai keterampilan "The 4Cs." "The 4Cs" meliputi berpikir kritis, kreativitas, komunikasi, dan kolaborasi [3]. Selain empat kompetensi yang disebutkan sebelumnya, literasi sains juga menjadi salah satu dari enam belas kecakapan hidup yang harus dimiliki peserta didik yang diidentifikasi dalam World Economic Forum. Literasi sains memandang pentingnya keterampilan berpikir dan bertindak yang melibatkan penguasaan berpikir dan menggunakan cara berpikir saintifik dalam mengenaldan menyikapi isu-isu sosial. Literasi sains penting bagi peserta didik untuk dapat memahami lingkungan, kesehatan, ekonomi, dan teknologi. Hal ini menunjukkan mendidik masyarakat untuk berliterasi sains menjadi suatu hal yang patut mendapatkan perhatian dan merupakan tujuan utama dalam setiap reformasi pendidikan sains [4].

Sementara itu, berdasarkan hasil evaluasi kemampuan literasi sains peserta didik di Indonesia yang dilakukan oleh PISA dalam tiga periode terakhir 
memperlihatkan tren yang semakin menurun. Hasil studi PISA 2012 menunjukkan sistem pendidikan Indonesia masih sangat jauh dari harapan. Hal itu terlihat dari 65 negara anggota PISA yang berpartisipasi, pendidikan Indonesia berada di peringkat 64. Begitu juga pada hasil PISA 2015, Indonesia menduduki peringkat 64 dari 72 negara yang ikut mengambil bagian walaupun nilai tes peserta didik mengalami kenaikan yang signifikan yakni 22,1 poin dari 382 menjadi 403 di tahun 2015 [5]. Namun pada tahun 2018 penurunan kembali terjadi. Peringkat Indonesia berada pada urutan 70 dari 78 negara dengan skor pencapaian 396, tujuh poin lebih rendah dibandingkan evaluasi tiga tahun sebelumnya [6]. Oleh karena itu, sikap gemar belajar dan ingin menambah informasi baru melalui berbagai sumber perlu dimunculkan dalam diri siswa. Guru perlu mencari strategi dan metode yang tepat untuk menumbuhkan sikap gemar belajar siswa tersebut. Kegiatan belajar yang bersifat parsipatoris dan antisipatoris perlu difasilitasi oleh guru, karena sesungguhnya sifat dasar seorang anak adalah memiliki rasa ingin tahu dan antusias untuk mencoba hal baru.

Berdasarkan hal di atas, maka diperlukan suatu strategi yang tepat untuk dapat meningkatkan kemampuan literasi sains peserta didik. Bahan ajar sebagai salah satu perangkat pembelajaran dan sumber belajar bagi peserta didik selayaknya memiliki peran penting dalam proses pembelajaran guna membantu guru dalam mengarahkan pembelajaran agar berjalan lebih optimal. Suharyadi menyebutkan bahwa beberapa buku ajar yang mengacu pada kurikulum lama menjejali peserta didik dengan konsep-konsep yang harus dihafal, dan tidak mengajak peserta didik berpikir sebagai proses mengkonstruksi pengetahuan dan pengalaman mereka untuk menemukan sendiri konsep-konsep yang harus dipahaminya dan menemukan makna serta keterkaitannya dengan kehidupan mereka secara individual, bermasyarakat dan bernegara. Untuk itu diperlukan pengembangan bahan ajar yang sesuai agar pengembangan kemampuan literasi sains peserta didik juga dapat ditingkatkan [7].

Salah satu bahan ajar yang dapat memfasilitasi peserta didik dalam kegiatan pembelajaran adalah lembar kegiatan peserta didik (LKPD). Pengembangan LKDP perlu memperhatikan dua aspek yakni desain dan langkah-langkah pengembangannya. Adapun dua hal yang perlu diperhatikan dalam mendesain pengembangan LKPD meliputi tingkat kemampuan membaca dan pengetahuan peserta didik. Langkah-langkah pengembangan LKPD meliputi penentuan tujuan pembelajaran, pengumpulan materi, penyusunan elemen atau unsur-unsur, serta pemeriksaan dan penyempurnaan [8].

Prastowo menyatakan bahwa LKPD yang dapat mengaktifkan peserta didik, mempermudah peserta didik untuk memahami materi ajar yang diberikan serta ringkas dan kaya tugas untuk berlatih merupakan LKPD yang diperlukan peserta didik selama menjalani proses pembelajaran di kelas [9]. Pengembangan LKPD literasi sains berbasis lesson study for learning community (LSLC) untuk dapat meningkatkan literasi sains siswa [10]. Saito, dkk menyatakan bahwa dengan melakukan kolaborasi dengan pola LSLC kompetensi literasi sains dapat ditanamkan pada siswa [11]. Dengan melalui tahapan plan, do, dan see, tim mampu mempersiapkan dan mengimplementasikan desain instruksional berbasis literasi sains yang baik [12].

Hal tersebut didukung oleh beberapa penelitian yang relevan terkait dengan penelitian ini yakni, Pertama penelitian yang dilakukan oleh Wardani menunjukkan pengembangan perangkat pembelajaran IPA terpadu dengan setting inquiry laboratorium bermuatan content local genius layak digunakan karena telah dikategorikan sangat valid, efektif dalam meningkatkan meningkatkan pemahaman konsep dan keterampilan proses sains siswa kelas VIII di SMP Negeri 4 Singaraja [13].

Kedua penelitian yang dilakukan oleh Khair menunjukkan bahan ajar IPA berbasis inkuiri layak digunakan karena telah dikategorikan sangat valid, efektif dalam meningkatkan hasil belajar dan keterampilan proses siswa, serta praktis digunakan dalam proses pembelajaran IPA pada kelas VB di SDN 4 Praya [14-16].

Berdasarkan hal tersebut, maka tujuan penelitian ini yaitu untuk menghasilkan LKPD literasi sains berbasis lesson study for learning community yang valid.

\section{METODE PENELITIAN}

Penelitian ini merupakan penelitian Research and Development ( $\mathrm{R} \& \mathrm{D})$. Research and Development adalah metode penelitian yang digunakan untuk menghasilkan produk tertentu dan menguji keefektifan produk tersebut. Rancangan penelitian dan pengembangan yang digunakan dalam penelitian ini adalah model 4D yang terdiri dari tahap define, design, develop, dan disseminate [17].

Berikut rincian tahapan dan instrumen yang akan digunakan pada masing-masing tahapan penelitian:

1) Define

Tahapan awal ini bertujuan untuk mengetahui dan mendefinisikan kebutuhan-kebutuhan dalam proses pembelajaran dan mengumpulkan informasi terkait LKPD yang akan dikembangkan. Untuk mendapatkan informasi tersebut digunakan instrumen berupa lembar observasi, lembar wawancara, dan studi kurikulum.

2) Design

Informasi yang didapatkan pada tahapan define terkait pengembangan LKPD berbasis literasi sains kemudian dikumpulkan dan dijadikan acuan untuk 
merancang LKPD berbasis literasi sains dengan pola lesson study for learning community.

\section{3) Develop}

Tujuan utama dalam tahap pengembangan yaitu untuk menghasilkan LKPD berbasis literasi sains dengan pola lesson study for learning community yang efektif dan layak untuk disebarluaskan. Instrumen yang digunakan untuk menguji keefektivitasan dalam LKPD yang telah dikembangkan yaitu angket terapan, tes keefektivitas LKPD ditinjau dari kemampuan literasi sains siswa (aspek kompetensi).

4) Disseminate

Setelah tahapan pengembangan selesai, maka dilanjutkan ke tahapan akhir yaitu diseminasi atau menyebarluaskan LKPD berbasis literasi sains dengan pola lesson study for learning community. Pada penelitian ini, tahapan diseminasi dilakukan melalui seminar, publikasi artikel hasil penelitian, pengajuan hak kekayaan intelektuan produk yang dikembangkan, dan menyebarluaskan produk tersebut pada mitra, dalam hal ini SDN 34 Cakranegara.

Tabel 1. Kriteria Kevalidan LKPD

\begin{tabular}{c|l}
\hline \multicolumn{1}{c}{ Skor } & \multicolumn{1}{c}{ Kriteria } \\
\hline $3,5<\mathrm{SR} \leq 4,0$ & Sangat Valid \\
$2,5<\mathrm{SR} \leq 3,5$ & Valid \\
$1,5<\mathrm{SR} \leq 2,5$ & Tidak Valid \\
$1,0<\mathrm{SR} \leq 1,5$ & Sangat Tidak Valid \\
\hline
\end{tabular}

Tabel 2. Kriteria Kepraktisan LKPD

\begin{tabular}{ll}
\hline Skor & Kriteria \\
\hline $3,5<\mathrm{SR} \leq 4,0$ & Sangat Praktis \\
$2,5<\mathrm{SR} \leq 3,5$ & Praktis \\
$1,5<\mathrm{SR} \leq 2,5$ & Tidak Praktis \\
$1,0<\mathrm{SR} \leq 1,5$ & Sangat Tidak Praktis \\
\hline
\end{tabular}

Analisis validitas LKPD terdiri dari validitas isi dan validitas konstruksi. Validitas isi untuk menganalisis apakah LKPD telah memenuhi prosedur pengembangan dan kesesuaian LKPD dengan teori, dilakukan secara teoritis oleh ahli. Validitas untuk melihat keterkaitan setiap komponen yang ada dalam LKPD dengan teori pembelajaran, dengan cara menghitung rata-rata skor dari validator. Penjumlahan rata-rata skor validator dirata-rata kembali. Perhitungan validasi LKPD dengan konversi rata-rata skor total menjadi nilai kualitatif menggunakan kriteria yang digunakan [16].

Data validitas LKPD diperoleh dengan menggunakan lembar validasi yang meliputi: lembar validasi LKPD. Hasil validasi oleh validator dengan menggunakan lembar validasi dibedakan menjadi empat kategori, yaitu:

$\begin{array}{ll}\text { Sangat Baik } & \text { : Skor } 4 \\ \text { Baik } & \text { : Skor } 3 \\ \text { Kurang } & \text { : Skor 2 } \\ \text { Sangat Kurang } & \text { : Skor } 1\end{array}$

\section{HASIL DAN PEMBAHASAN}

Penelitian ini mengembangkan LKPD LKPD berbasis literasi sains dengan pola lesson study for learning community materi perpindahan kalor kelas V. Berikut pemaparan setiap tahap yang dilakukan.

\section{Tahap Define (Pendefinisian)}

Analisis yang dilakukan terdiri dari lima langkah pokok, yaitu: analisis masalah, analisis peserta didik, analisis konsep, analisis tugas dan perumusan tujuan pembelajaran.

Pertama, analisis masalah yang dilakukan dalam tahap ini adalah melakukan wawancara pada guru untuk mendapatkan informasi tentang kondisi dan fakta pembelajaran IPA SD di lapangan. Informasi yang didapatkan digunakan untuk menganalisis masalah-masalah yang timbul dalam pembelajaran IPA SD. Setelah melalui proses observasi dan wawancara ditemukan bahwa dalam pembelajaran IPA SD dapat didefinisikan beberapa masalah, antara lain : (1) keterlibatan peserta didik dalam kegiatan pembelajaran masih rendah sehingga peserta didik cenderung pasif, (2) belum berkembangnya keterampilan berpikir (literasi sains) peserta didik berkaitan dengan materi yang dibahas (3) bahan ajar yang digunakan berupa buku paket dan LKPD dari penerbit tertentu yang lebih ditekankan pada materi dan soal-soal sehingga tidak menunjukkan kegiatan peserta didik dalam proses pengembangan keterampilan berpikir (4) metode pembelajaran yang digunakan masih didominasi dengan metode konvensional atau teacher centered. Permasalahan tersebut dijadikan sebagai dasar dalam menentukan LKPD yang dibutuhkan agar dalam penerapannya tepat dan efisien.

Kedua, analisis peserta didik yang dilakukan dengan wawancara, ditemukan fakta bahwa peserta didik di SD Negeri 34 Cakranegara memiliki motivasi yang cukup tinggi dalam mengikuti kegiatan pembelajaran di kelas, tingkat intelektual sedang, kemampuan bekerja sama dan bersosialisasi cukup tinggi. Beberapa fakta tersebut di atas dapat dijadikan sebagai acuan untuk mengembangkan LKPD literasi sains yang mampu mengembangkan keterampilan berpikir dan kemampuan bekerja dalam kelompok.

Ketiga, analisis konsep berisi identifikasi konsep-konsep utama yang diajarkan yang disusun secara sistematis dan rinci. Konsep-konsep yang berhubungan dengan kompetensi dasar yang dipilih yaitu perpindahan kalor.

Keempat, analisis tugas mengkaji tugas-tugas berupa kompetensi yang dikembangkan dalam proses pembelajaran. Kompetensi yang dikembangkan berdasarkan kurikulum SD untuk kelas V yakni KD 
3.6 : menerapkan konsep perpindahan kalor dalam kehidupan sehari - hari.

Kelima, perumusan tujuan pembelajaran digunakan sebagai pijakan untuk mendesain LKPD. Tujuan pembelajaran yang disusun berdasarkan KD yang digunakan antara lain antara lain peserta didik mampu menganalisis konsep perpindahan kalor dalam suatu fenomena ilmiah dengan tepat, eserta didik mampu merancang sebuah penyelidikan ilmiah mengenai konsep perpindahan kalor dengan tepat, peserta didik mampu menuliskan hasil pengamatan dalam sebuah penyelidikan ilmiah dengan tepat dan peserta didik mampu menginterpretasikan data dalam sebuah penyelidikan ilmiah dengan tepat.

\section{Tahap Design (Perancangan)}

Pada tahap ini dilakukan perancangan desain LKPD literasi sains. Secara garis besar komponenkomponen pada tahap desain awal Lembar Kerja Peserta didik (LKPD) literasi sains berbasis lesson study for learning community (LSLC) ini meliputi judul LKPD, Kompetensi Dasar (KD), indikator pembelajaran, tujuan pembelajaran, petunjuk penggunaan modul, studi kasus, percobaan sederhana, pertanyaan dan kesimpulan. Studi kasus dalam bagian LKPD merupakan pengembangan indikator kompetensi literasi sains yakni menjelaskan fenomena ilmiah. Pada bagian percobaan sederhana peserta didik dapat mengembangkan kompetensi literasi dalam merancang dan melakukan penyelidikan ilmiah serta menafsirkan data dan bukti ilmiah.

\section{Tahap Develop (Pengembangan)}

Tahap pengembangan ini bertujuan untuk menghasilkan perangkat pembelajaran yang lebih baik setelah melalui proses validasi dan ujicoba lapangan. Perangkat pembelajaran yang telah dirancang divalidasi dan direvisi berdasarkan masukan ahli. Selanjutnya diujicobakan secara terbatas ke SD
Negeri 34 Cakranegara untuk melihat kepraktisan LKPD yang dikembangkan. Berikut ini data yang diperoleh yang terdiri dari data hasil validasi ahli (kelayakan) dan kepraktisan :

\section{Validasi LKPD}

Proses validasi melibatkan 1 validator ahli. Ahli ini kemudian memvalidasi kebenaran isi, format, bahasa dan kegrafisan LKPD literasi sains yang dikembangkan peneliti. Validator memberikan penilaian terhadap LKPD literasi sains yang dikembangkan dengan mengisi angket serta meminta pendapat, kritik serta saran untuk perbaikan. Angket diisi dengan memberikan tanda cek list $(\sqrt{ })$ pada kolom yang sesuai dengan penilaian yang diberikan. Skor tertinggi adalah 4 dan skor terendah adalah 1 untuk masing-masing pernyataan. Skor total yang diberikan validator kemudian dirata-ratakan untuk mendapatkan skor rata-rata. Skor rata-rata ini kemudian dikonversi menjadi nilai skala 4. Ketentuan dan tata acara penilaian ini berlaku untuk semua data hasil validasi. Rekapitulasi hasil validasi kevalidan LKPD literasi sains yang dikembangkan disajikan pada Gambar 1.

Hasil uji validitas ahli menunjukkan hasil yang sangat valid dengan skor akhir 3,6. Selain pemberian skor dan kategori, dalam tahapan ini juga tim bersama validator melakukan reflkesi (see) untuk menjadi dasar perbaikan produk. Berikut adalah beberapa catatan diberikan oleh validator untuk perbaikan produk itu sendiri, di antaranya: 1) menambahkan gambar pada LKPD untuk memudahkan siswa mengenali alat dan bahan yang akan dipilih; 2) mengganti penggunaan pewarna dengan biji-bijian (kedelai); 3) memperbaiki redaksi pertanyaan pada studi kasus 2 .

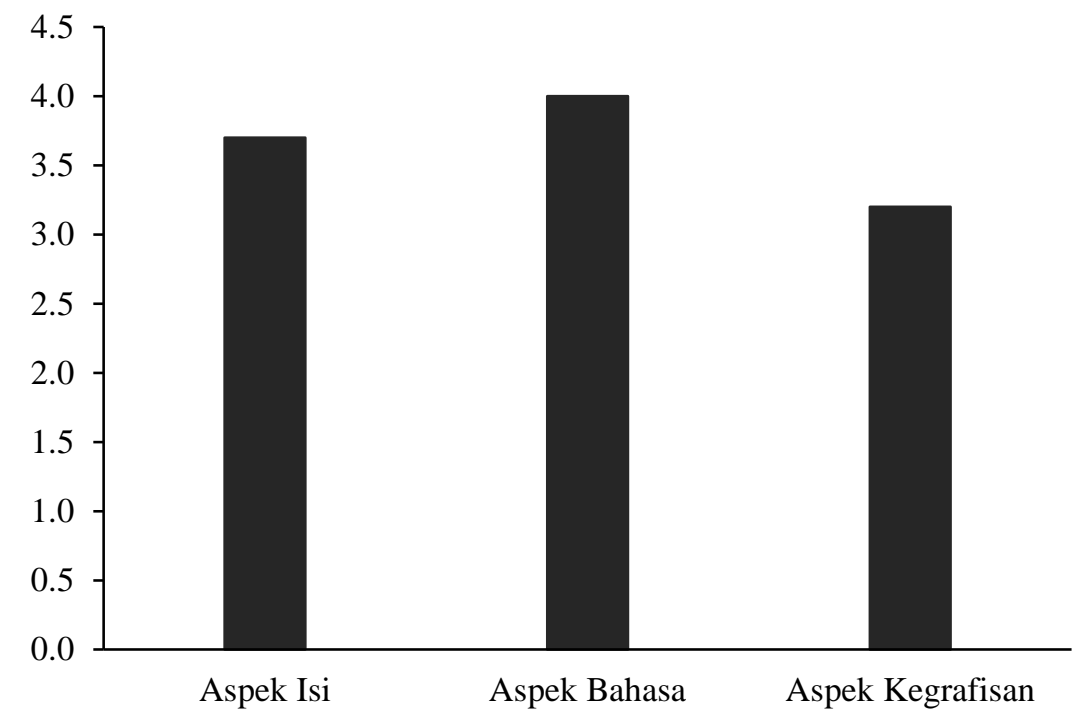

Gambar 1. Skor Rata-Rata Penilaian Validasi LKPD 


\section{Kepraktisan LKPD}

Data kepraktisan ujicoba produk terdiri atas data respon guru terhadap kesesuaian isi materi, struktur dan bahasa LKPD literasi sains pada materi perpindahan kalor yang dikembangkan serta respon peserta didik terhadap uji keterbacaan dan kemenarikan produk LKPD literasi sains setelah dioperasionalkan di lapangan. Data respon guru dan peserta didik terhadap penggunaan LKPD literasi sains materi perpindahan kalor dihimpun setelah proses pembelajaran selesai. Responden yang dilibatkan untuk mengetahui respon guru terhadap penggunaan LKPD literasi sains adalah satu orang guru kelas V SD Negeri 34 Cakranegara sedangkan jumlah responden keterbacaan dan kemenarikan LKPD literasi sains yang dikembangkan terdiri atas delapan responden/peserta didik Hasil penelitian menunjukkan respon guru dan respon peserta didik terhadap penggunaan LKPD termasuk dalam kategori sangat praktis. Rekapitulasi hasil kepraktisan ujicoba produk disajikan dalam Tabel 3 berikut ini.

Tabel 3. Data Kepraktisan LKPD Literasi Sains

\begin{tabular}{llll}
\hline No. & Instrumen & $\begin{array}{l}\text { Skor } \\
\text { akhir }\end{array}$ & Ketegori \\
\hline 1. & $\begin{array}{l}\text { Angket respon guru } \\
\text { terhadap LKPD literasi } \\
\text { sains }\end{array}$ & 3.8 & $\begin{array}{l}\text { Sangat } \\
\text { praktis }\end{array}$ \\
2. & $\begin{array}{l}\text { Angket respon peserta } \\
\text { didik terhadap LKPD } \\
\text { literasi sains }\end{array}$ & 3.5 & $\begin{array}{l}\text { Sangat } \\
\text { Praktis }\end{array}$ \\
\hline
\end{tabular}

\section{Tahap disseminate}

Tahapan ini yaitu menyebarluaskan produk LKPD literasi sains berbasis LSLC yang telah dikembangkan. Untuk dapat melakukan kegiatan ini, produk LKPD tersebut harus telah tervalidasi oleh ahli kemudian diuji kepraktisan dan keefektivannya. Adapun uji efektivitas tersebut harus dilakukan dalam skala klasikal. Terkait dengan hal tersebut, dalam penelitian ini, uji efektifitas dalam cakupan klasikal belum dapat dilaksanakan terkait kendala covid 19 yang tidak memungkinkan siswa dihadirkan dalam kelas. Oleh karena itu, disseminasi ini akan dilakukan berdasarkan hasil uji validitas dan keterterapan yang kemudian produk LKPD ini sendiri akan diserahkan untuk sekolah mitra, yakni SDN 34 Cakranegara. Hasil ini selaras dengan hasil penelitian sebelumnya [19-20]. Berdasarkan uraian diatas, maka diperoleh LKPD literasi sains berbasis lesson study for learning community sangat valid dan praktis.

\section{KESIMPULAN}

Berdasarkan hasil penelitian dan pembahasan dapat disimpulkan bahwa: 1) LKPD literasi sains berbasis lesson study for learning community dinyatakan valid dengan skor rata-rata $3,60,2$ ) kepraktisan terhadap LKPD yang dikembangkan berada pada kriteria 3,80 oleh guru dan 3,50 oleh peserta didik. Berdasarkan hasil penelitian dapat disimpulkan bahwa LKPD literasi sains berbasis lesson study for learning community sangat valid dan praktis.

\section{DAFTAR PUSTAKA}

[1] Jufri, A. W., Qadri, B. A., Hikmawati, M. M., \& Sriwarthini, N. L. P. N. (2020). Belajar dan Pembelajaran: Modal Dasar Menjadi Guru Profesional. Mataram: Sanabil.

[2] Wardani, K. S. K., Sriwarthini, N. P. N., Rahmatih, A. N., \& Sadia, I. W. (2020, August). The Effect of Problem Based Learning Model with Character Education on Science Process Skills. In 1st Annual Conference on Education and Social Sciences (ACCESS 2019) (pp. 298-301). Atlantis Press.

[3] Redhana, I. W. (2019). Mengembangkan keterampilan abad ke-21 dalam pembelajaran kimia. Jurnal Inovasi Pendidikan Kimia, 13(1).

[4] Pratiwi, S. N., Cari, C., \& Aminah, N. S. (2019). Pembelajaran IPA abad 21 dengan literasi sains siswa. Jurnal Materi dan Pembelajaran Fisika, 9(1), 34-42.

[5] Organisation for Economic Co-operation and Development. (2016). PISA 2015 results in focus. PISA.

[6] Schleicher, A. (2019). PISA 2018: Insights and Interpretations. OECD Publishing.

[7] Suharyadi, P. A., dan Hernani.(2013). Pengembangan Buku Ajar Berbasis Kontekstual Pada Pokok Bahasan Asam dan Basa. Jurnal Riset dan Praktik Pendidikan Kimia, 1(1), 60-68.

[8] Afifah, R. N. (2015). Pengembangan Lembar Kerja Siswa (LKS) Ilmu Pengetahuan Alam Berbasis Metode Percobaan. Universitas PGRI Yogyakarta.

[9] Prastowo, A. (2011). Panduan kreatif membuat bahan ajar inovatif.

[10] Dragoş, V., \& Mih, V. (2015). Scientific literacy in school. Procedia-Social and Behavioral Sciences, 209, 167-172.

[11] Saito, E., Watanabe, M., Gillies, R., Someya, I., Nagashima, T., Sato, M., \& Murase, M. (2015). School reform for positive behaviour support through collaborative learning: utilising lesson study for a learning community. Cambridge journal of education, 45(4), 489-518.

[12] Hadiprayitno, G., Khair, B. N., \& Sukri, A. (2020, February). Student 
Perspectives in the Implementation of Learning Based on Lesson Study at Madrasah Tsanawiyah Negeri 2 Mataram. In 3rd International Conference on Learning Innovation and Quality Education (ICLIQE 2019) (pp. 462-471). Atlantis Press.

[13] Wardani, K. S. K., Sadia, I. W., \& Suastra, I. W. (2016, August). Pengembangan perangkat pembelajaran IPA terpadu dengan setting inquiry laboratorium bermuatan content local genius untuk meningkatkan pemahaman konsep dan keterampilan proses sains siswa SMP. In Prosiding Seminar Nasional MIPA.

[14] Khair, B. N., Susilo, H., \& Suarsini, E. (2018). Pengembangan Bahan Ajar IPA Berbasis Inkuiri Untuk Siswa Kelas V SD. ELSE (Elementary School Education Journal): Jurnal Pendidikan dan Pembelajaran Sekolah Dasar, 2(1), $97-$ 108.

[15] Hasanah, J., Jamaludin, J., \& Prayitno, G. H. (2019). Bahan Ajar IPA Berbasis Inkuiri Terstruktur Untuk Meningkatkan Literasi Sains Peserta Didik SMP. Jurnal Pijar MIPA, 14(2), 18-24.
[16] Senjaharmini, D. A., Jufri, A. W., \& Jamaluddin, J. (2019). Efektivitas Bahan Ajar IPA Berbasis Inkuiri Terbimbing (BAIPABIT) untuk Meningkatkan Kemampuan Berargumen Peserta Didik. Jurnal Pijar Mipa, 14(2), 55-59.

[17] Sugiyono, M. (2015). penelitian \& pengembangan (Research and Development/R\&D). Bandung: Penerbit Alfabeta.

[18] Candiasa, M. (2010). Statistik Multivariat Disertai Petunjuk dengan SPSS. Singaraja: Program Pascasarjana, Universitas Pendidikan Ganesha.

[19] Pratiwi, S. N., Cari, C., \& Aminah, N. S. (2019). Pembelajaran IPA abad 21 dengan literasi sains siswa. Jurnal Materi dan Pembelajaran Fisika, 9(1), 34-42.

[20] Departemen Pendidikan, I. P. A., \& Hamka, J. P. D. (2018). Implementasi Literasi Sains Framework PISA 2015 melalui Lesson Study Dalam Pembelajaran IPA di SMP: Plan; Do; See. Jurnal SEMESTA, 1(02), 12-18. 